\title{
Electrochemical Detection of DNA Hybridization via Bis-intercalation of a Naphthylimide-functionalized Viologen Dimer
}

\section{Supporting Information}

\author{
Eli G. Hvastkovs ${ }^{\mathrm{a}}$ and Daniel A. Buttry* \\ Department of Chemistry (3838), University of Wyoming, 1000 E. University Ave., \\ Laramie, Wyoming 82070 \\ * - address correspondence to this author at buttry@uwyo.edu \\ a - Current address: Department of Chemistry, U-3060, 55 North Eagleville Rd., \\ University of Connecticut, Storrs, CT. 06269-3060
}

\begin{abstract}
Information included in this supplementary file includes the synthesis procedure used to obtain and purify the naphthylimide viologen dimer (NIV). Also, the spectroscopic characterization of both the intermediate compounds and the final NIV compound using ${ }^{1} \mathrm{H}$ nuclear magnetic resonance (NMR) and matrix assisted laser desorption ionization (MALDI)-time of flight (TOF) methods are discussed.
\end{abstract}




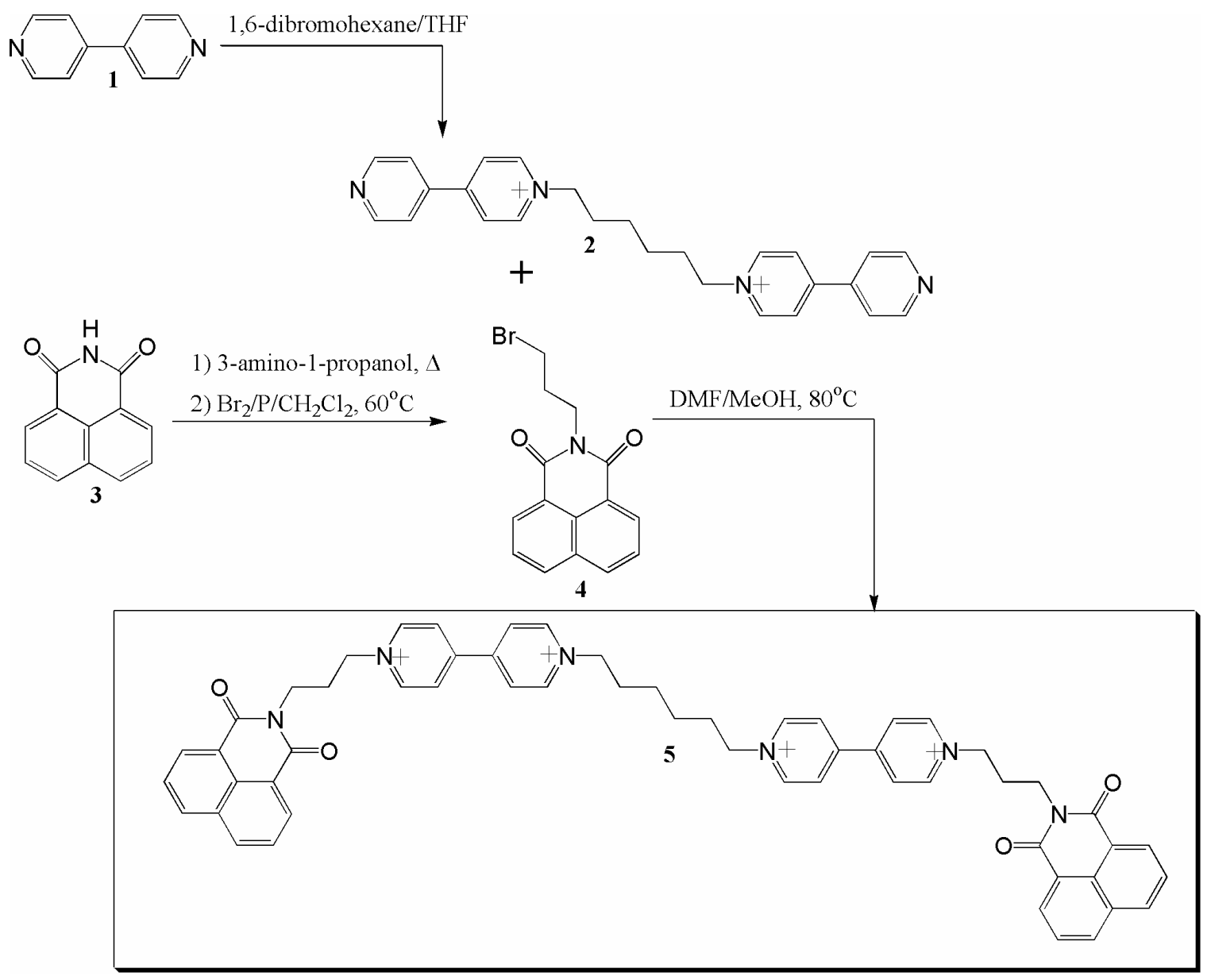

Scheme S1. Synthesis of intermediate compounds (2 and 4) and final NIV compound (5).

\section{NIViologen synthesis:}

Scheme S1 diagrams the synthesis steps involved in preparing the NIV compound. The di-viologen backbone template molecule $\left(\mathrm{VC}_{6} \mathrm{~V}^{2+}, 2\right)$ was synthesized by reacting 4,4'-bipyridine (1) in an 11:1 molar excess with 1,6-dibromohexane refluxed in THF for 8 hours. The product was insoluble and was collected by filtration and dried under high vacuum. The product was a yellow powder with the molecular formula $\mathrm{V}^{+} \mathrm{Br}^{-} \mathrm{C}_{6} \mathrm{H}_{12} \mathrm{~V}^{+} \mathrm{Br}^{-}\left(\mathrm{V}^{+}=4,4\right.$ ' bipyridinium or viologen $)$. The yield was approximately $99 \%$ with a purity of $95 \%$. The presence and purity of the product were confirmed with ${ }^{1} \mathrm{H}$ NMR (400 MHz Bruker Avance). ${ }^{1} \mathrm{H}$ NMR (DMSO, ppm): 9.3 (d, bipyridinyl, 4H), 
8.9 (d, bipyridinyl, 4H), 8.7 (d, bipyridinyl, 4H), 8.1 (d, bipyridinyl, 4H), 4.7 (t, methylene adjacent to $\mathrm{N}, 4 \mathrm{H}), 2.0$ (m, methylene beta to $\mathrm{N}, 4 \mathrm{H}), 1.4$ (m, methylene gamma to $\mathrm{N}, 4 \mathrm{H})$.

Naphthalic anhydride (Sigma, 3) was reacted in a 1:1 molar ratio with 3-amino1-propanol by combining the two in a round bottom flask and heating with a flame. The resulting product was naphthyl imide propanol and was recrystallized from ethanol. The yield and purity of the product was $100 \%$. The crystals were white. ${ }^{1} \mathrm{H}$ NMR (DMSO, ppm): 8.5 (dd, naphthyl, 4H), 7.9 (t, naphthyl, 2H), 4.5 (t, hydroxyl, 1H), 4.1 (t, methylene adjacent to N, 2H), 3.5 (quartet, methylene adjacent to $\mathrm{O}, 2 \mathrm{H}$ ), 1.8 (quintet, remaining methylene, $2 \mathrm{H}$ ).

The bromination of the hydroxyl group was performed following a previously established protocol with some modifications. ${ }^{1}$ The naphthyl imide propanol compound produced above $(0.660 \mathrm{~g}=.00277 \mathrm{~mol})$ and atomic phosphorus $(0.0462 \mathrm{~g}=.0015 \mathrm{~mol})$ were dissolved in $5 \mathrm{~mL}$ dried chloroform in a three-necked flask. $210 \mu \mathrm{L}$ of bromine (.00320 mol) in $2.5 \mathrm{~mL}$ chloroform was added slowly over a period of $1 \mathrm{hr}$. with some agitation of the flask to distribute the bromine evenly into solution. Upon addition of the bromine, the solution turned a tan color. This mixture was allowed to reflux for $3 \mathrm{hrs}$. The presence of product was tested using TLC. The desired product was removed from the reaction with an organic/aqueous extraction. The organics were collected and rinsed again with $\mathrm{H}_{2} \mathrm{O}$ adding $\mathrm{NaCl}$ to separate the water/chloroform mixture. The organics were dried with $\mathrm{MgSO}_{4}$ and filtered. The resulting crude product was collected by removing the solvent under high vacuum. The brominated naphthyl imide propyl compound (4) was recrystallized from ethanol. The yield was approximately 50\%, and 
the purity was approximately $98 \%$. The resulting product is a tan powdery substance. ${ }^{1} \mathrm{H}$ NMR (DMSO, ppm): 8.6 (d, naphthyl, 2H), 8.2 (d, naphthyl, 2H), 7.8 (dd, naphthyl, 2H), 4.4 (t, methylene adjacent to N, 2H), 3.5 (t, methylene adjacent to Br), 2.4 (quintet, remaining methylene, $2 \mathrm{H})$.

2 and 4 were refluxed in a 1:4 molar ratio in $1 \mathrm{~mL}$ DMF and $0.5 \mathrm{~mL}$ methanol under Argon for 24 hours. The resulting crude product was rinsed with chloroform to remove excess $\mathbf{3}$ starting material and was recrystallized from methanol. The final product was 5 with the following formula $\mathrm{NIC}_{3} \mathrm{H}_{6} \mathrm{~V}^{2+} \mathrm{Br}_{2}{ }^{2-} \mathrm{C}_{6} \mathrm{H}_{12} \mathrm{~V}^{2+} \mathrm{Br}_{2}{ }^{2-} \mathrm{C}_{3} \mathrm{H}_{6} \mathrm{NI}$, abbreviated NIV (NI = naphthyl imide, $\mathrm{V}=$ Viologen). The yield was approximately $20 \%$. The purity was approximately $98 \%$. The final product was a tan powder. ${ }^{1} \mathrm{H}$ NMR (DMSO, ppm): 9.5 (dd, pyridinyl, 8H), 8.8 (dd, pyridinyl, 8H), 8.5(t, naphthyl, 8H), 7.9 (t, naphthyl, 4H), 4.8(t, methylene adjacent to $\mathrm{N}$ in propyl linker, 4H), 4.7 (t, methylene adjacent to $\mathrm{N}$ in hexyl linker, 4H), 4.2 (t, methylene adjacent to naphthyl compound, $4 \mathrm{H}$ ), 2.4 (m, remaining methylene in propyl linker, $4 \mathrm{H}), 2.0$ (m, methylene in hexyl linker, 4H), 1.4 (m, remaining methylene in hexyl linker, 4H).

MALDI-TOF (Applied Biosystems Voyager System 6217, linear mode) was employed as well to characterize the product. The matrix used was $\alpha$-cyano-4hydroxycinnamic acid in a 1:3 compound to matrix ratio. The laser reduced the viologens due to the photoactivity of the compound. The peak corresponding to the desired product was seen at $\mathrm{M}^{+}=872$, which corresponds to the desired product with no bromine counter ions and a +1 charge. 
1. Braun, G. Org. Syn., 1943, Coll. Vol. 2, 308. 